\title{
Improving Teacher's Ability in Developing Innovative RPP During The Covid-19 Pandemic Through Academic Supervision Program in SMAN 1 Puloampel Academic Year 2020/2021
}

\section{Rohadi $^{1}$}

${ }^{1}$ SMAN 1 Puloampel, Serang Regency, Banten Province

\section{ARTICLE INFO}

\section{Keywords:}

Learning

Implementation Plan

Academic Supervision

Innovative

\begin{abstract}
This School Action Research (PTS) aims to improve the ability of teachers to develop innovative lesson plans through academic supervision (individual scientific and technical supervision models) during the COVID-19 pandemic. This research was conducted in four stages, namely planning, implementation, observation and reflection, and was carried out in two cycles. The research subjects were 4 science teachers and 4 social studies teachers in my school, namely SMAN 1 Puloampel, Serang district, Banten province. The components of the innovative RPP assessment consist of formulating indicators, formulating learning steps (KBM), allocating time, determining learning resources, formulating teaching methods, and formulating assessments while the innovations that are expected in making the RPP are RPPs that can produce, combine, have added value, something new and answers problems and is integrated with Strengthening Character Education (PPK), oriented to HOTS or improving students' higher thinking skills and having 21st-century skills. In the first cycle, the researcher observed an increase in teacher competence in making innovative lesson plans. The results of observations of individual RPP assessments in the first cycle showed an average value of $68.4 \%$. In the second cycle, the teacher's average value increased in making lesson plans, which was $77.6 \%$. While the classical lesson plan completeness assessment from cycle I and cycle II showed a good average value of $73 \%$. This proves that academic supervision can improve the ability of teachers in preparing innovative RPP (Learning Implementation Plans).
\end{abstract}

This is an open access article distributed under the terms of the Creative Commons Attribution 4.0 International License, which permits unrestricted use, distribution, and reproduction in any medium, provided the original work is properly cited. @ 2021 Rohadi

\section{INTRODUCTION}

RPP or Lesson Plan is the initial activity in carrying out learning activities, the success of a lesson is determined by the quality of the plans made. That is why the preparation of lesson plans is important for educators. One thing that is not negotiable is that RPP must be made by educators with a learning model that has components in the preparation of the RPP. Educators describe and develop basic competencies into indicators of competency achievement and learning objectives.

\footnotetext{
${ }^{1}$ Corresponding author's address: SMA Negeri 1 Puloampel, Serang Regency, Banten Province, Indonesia e-mail: rohadisrg@gmail.com
} 
The lesson plans prepared by educators contain matters directly related to learning activities as an effort to achieve and master competencies for students.

RPP is developed by teachers in the education unit. Teachers in education units are obliged to prepare RPPs that are innovative, systematic and strive to adapt to the Circular of the Minister of Education and Culture number 14 of 2019, namely making RPPs that are more simplified or demanding more innovative teachers so that learning takes place interactively, inspiring, fun, challenging, motivating participants, students to participate actively and provide sufficient space for the initiative, creativity, and independence by the talents, interests and physical and psychological development of students.

Learning planning is a very important step before the implementation of learning. Careful planning is needed so that the implementation of learning runs effectively. Learning planning is poured into the RPP. RPP generally contains Core Competencies (KI), Basic Competencies (KD), indicators to be achieved, materials to be studied, learning methods, learning steps, learning media, and learning resources and assessments.

However, education in Indonesia is currently experiencing a very serious disruption with the outbreak of a disease that has hit the world, namely the Covid-19 Pandemic. This has made several countries implement policies to impose lockdowns to prevent the spread of the coronavirus. In Indonesia, the government encourages people to work from home. It is also recommended to pray at home during the Covid-19 Pandemic. This is all done to suppress the spread of a very dangerous virus.

The practical problem encountered in schools today is how to optimize the implementation of learning during the Covid-19 pandemic. As it is known that the Covid-19 Pandemic period demands a change in the learning system which was originally in the form of conventional face-toface learning to learning that utilizes ICT (Information and Communication Technology).

So far, teachers who teach in schools rarely get the opportunity to attend various Teacher Professionalism Improvement Trainings. This causes many teachers who do not know and understand the preparation/making of RPP properly and completely and are still confused with the steps for learning RPP Online version which are adapted to the Covid-19 Pandemic period.

Some teachers mostly adopt lesson plans from the internet or other teachers. The researcher knows when conducting academic supervision at the school that the author leads at SMAN 1 Puloampel, Serang Regency, Banten Province. These problems have a big influence on the implementation of the learning process.

Based on the description above, the authors are interested in improving the ability of teachers to develop innovative RPP during the Covid-19 Pandemic through Academic Supervision at SMAN 1 Puloampel in the 2020-2021 academic year. Academic Supervision is a series of activities by principals in helping teachers develop their ability to manage the learning process to achieve learning objectives.

\section{Innovative RPP Concept}

Before teaching the teacher must first design a Learning Implementation Plan, therefore, according to experts who have been put forward by Mulyasa $(2007$, p. 183) who revealed that RPP is a plan for describing teaching procedures and managed to achieve one or more basic competencies set out in the standard competencies and described in the syllabus.

Then according to E. Kosasih (2014, p. 144) that RPP is a learning plan whose development refers to a certain KD (Basic Competence) in the curriculum/syllabus. On the Regulation of the Minister of Education and Culture, Number 22 of 2016 concerning Standards for Primary and Secondary Education, the Learning Implementation Plan (RPP) is a face-to-face learning activity plan for one 
or more meetings. RPP was developed from the syllabus to direct student learning activities to achieve Basic Competence (KD).

Meanwhile, according to the latest circular from the Minister of Education and Culture number 14 of 2019 the Learning Implementation Plan or RPP is a face-to-face learning activity plan for one or more meetings. Every educator in the education unit is obliged to prepare a complete and systematic lesson plan so that learning takes place interactively, inspiring, fun, challenging, efficient, motivating students to participate actively, and providing sufficient space for the initiative, creativity, and independence according to their talents, interests, and the physical and psychological development of students.

In the latest Circular from the Minister of Education and Culture number 14 of 2019 concerning the Simplification of Learning Implementation Plans (RPP), teachers can freely choose, create, use, and develop RPP formats independently for maximum success of students. The RPP that has been made by Permendikbud number 22 of 2016 can still be used and can also be adapted to the latest provisions. This means that there is no standard format for making lesson plans and the most important thing is that a teacher understands the meaning of the lesson plans themselves.

As for the learning activities, we still refer to:

1) Integrated into Strengthening Character Education or PPK, namely Religious, Nationalist, Independent, Mutual Cooperation and Integrity.

2) Improving 21st-century skills, namely $4 \mathrm{C}$ (Creative and Innovation, Critical thinking and Problem Solving, Communicative and Collaborative).

3) Literacy, Numeration and Character.

4) HOTS (High Order Thinking Skills).

5) Recognizing Potential Intelligence.

\section{Innovation}

The word innovation comes from the English word "innovate" which means introducing something new, while innovative means updating. Then the words "innovate" and "innovative" are Indonesian by undergoing a written change to become "innovative" which means introducing something new. Meanwhile, people who carry out renewal are called "innovators".

According to Schumpeter, innovation has meaning as an effort to create and implement something into a combination so that with innovation one can add value to products, services, work processes, and educational policies not only for educational institutions but also stakeholders and society.

Wina Sanjaya in her book curriculum and learning, innovation is defined as something new in certain social situations and is used to answer or solve a problem. Meanwhile, according to M. Rogers, an innovation is an idea, method, action, product, or service that is considered new by the individual or group that adopts it. A person's perception of a new idea is determined by his reaction to action. If the idea is considered new by the person, then it is said to be an innovation.

The indicators for the preparation of innovative lesson plans are based on model theories and innovative learning approaches, including multiple intelligence-based models, problem-based learning, project-based learning, cooperative learning types number head together, role-playing type, student teams achievement development (STAD) type, two stay two stray type, jigsaw type, make a match type, picture to picture type, contextual teaching and learning, discovery learning ), and several other models.

Innovative RPP (Learning Implementation Plan) can be interpreted as an activity to prepare for the implementation of learning that applies the latest learning elements in the $21^{\text {st-century and is }}$ integrated into the components and stages of learning that will be carried out to achieve the stated goals. 
If we conclude and combine based on experts that RPP with the innovative theory itself is a learning design that can produce, combine learning methods, provide added value, produce something new and answer problems. This is because learning will be more alive and meaningful. The criteria for preparing RPP are said to be innovative if in Formulating Indicators, Formulating KBM Steps, Allocating Time, Determining Learning Resources, Formulating Teaching Methods and Formulating Assessments, there are elements of innovation that have been mentioned earlier.

The followings are the characteristics of innovative learning designs and their application lesson plans, namely:

1) Learner-centered.

2) HOTS oriented.

3) Integrating Information and Communication Technology (ICT).

4) Oriented on learning skills and developing Skills $21^{\text {st-century. }}$

5) Develop literacy skills.

6) Strengthening Character Education (PPK).

\section{The concept of Academic Supervision}

Academic supervision is a series of activities to help teachers develop their ability to manage the learning process to achieve learning objectives (Daresh, 1989, Glickman, et al. 2007). Academic supervision is inseparable from teacher performance assessment in managing learning.

According to Ngalim Purwanto (2006, 198:103), supervision is a coaching activity that is planned to assist teachers and other school employees in doing their jobs effectively. Supervision is defined as a service provided by leaders to help teachers, people who are led to become capable teachers (personnel) by the development of science in general and education, in particular, to be able to increase the effectiveness of the teaching and learning process in schools. Here supervision is defined as a service effort and assistance in the form of guidance from superiors or school principals to school personnel or teachers and other officers.

Meanwhile, according to Boardman, Douglass and Bent (1961) quoted by (Maunah, 2009:20) define educational supervision as follows: Efforts to encourage, coordinate and guide the development of teachers both individually and in groups so that they get a better and effective understanding to carry out all teaching functions so that they are more likely to encourage and guide the development of students towards rich and intelligent participation in society.

From the definition of supervision described above, of course, supervision has a very strategic role in improving the quality and quantity of an organization or activity. From this understanding, it also shows that supervision is not a momentary activity such as inspection, but is a continuous and continuous activity so that teachers always develop in doing assignments and can solve various educational and teaching problems effectively and efficiently.

Implicitly the definition of supervision has new insights and views on supervision that contain main ideas, such as promoting teacher professional growth, developing democratic leadership, releasing energy, and solving various problems related to the effectiveness of the teaching and learning.

In essence, supervision besides being in the form of coaching towards improving the educational situation in general and improving the quality of learning in particular, the essence of supervision also contains several main activities, namely continuous coaching, professional development of personnel, improvement of teaching and learning situations with the ultimate goal of achieving educational goals.

So it can be concluded that supervision is a professional service. These professional services can be in the form of assisting school personnel in improving their abilities so that they are better able to maintain and make changes to the school administration to improve the achievement of school 
goals. In other words, that educational supervision is a coaching activity that is planned to assist teachers and other school staff in carrying out their work effectively process.

\section{Academic Supervision Models}

Academic supervision by the principal can be carried out with several kinds of models, approaches, methods and techniques. The academic supervision model can be interpreted as a reference that can be used by school principals in carrying out academic supervision.

Sahertian (2008) divides the supervision model into four forms consisting:

1) Conventional supervision model

The supervision model adheres to the notion that the supervisor is someone who has the power to determine the fate of the teacher. In the practice of supervision, supervisors with a conventional style will find fault with teachers and often even spy on teachers. This spying behaviour is referred to as supervision or also often referred to as corrective supervision.

2) Artistic supervision model

The artistic supervision model requires a supervisor in carrying out his duties to be knowledgeable, skilled, and have a wise attitude. As revealed by Jasmani and Mustofa (2013) the artistic supervision model is based on working for others (working for the other), working with others (working with the other), and working through the other. Therefore, the implementation of supervision certainly contains an artistic value.

3) Scientific supervision model

The scientific supervision model is a supervision model that can be used by supervisors to collect data or information and assess teacher performance by distributing questionnaires. Scientific supervision has the following characteristics:

a. Implemented in a planned and sustainable manner.

b. Systematic and using certain procedures and techniques

c. Using data collection instruments.

d. Can collect objective data.

4) Clinical supervision model

Clinical supervision is supervision that is carried out based on complaints or problems from teachers submitted to supervisors. Clinical supervision is a form of supervision that is focused on improving learning through a systematic cycle, in planning intensive and careful observation and analysis of real teaching performances, and aims to make changes rationally.

\section{Academic Supervision Techniques}

There are various kinds of academic supervision techniques to develop teacher abilities. This includes staff meetings, supervision visits, teacher assessments, demonstrations of learning, curriculum development, development of learning guides, workshops, inter-class visits, and school community surveys.

Meanwhile, according to Gwyn, the supervision techniques are grouped into two groups, namely individual supervision techniques and group supervision techniques.

\section{Individual Supervision Techniques}

Supervision techniques that are grouped as individual techniques include class visits, class observations, individual meetings, interclass visits, and self-assessment. The following will explain the basic meanings briefly one by one.

1) Class visit

Class visits are a teacher coaching technique by the principal schools, supervisors, and other coaches to observe the implementation of the teaching and learning process so that obtain the necessary data in the context of coaching teacher. This class visit can be carried out 
by: notification or without prior notice, and can also based on an invitation from the teacher himself.

2) Class observation

Class observation can simply be interpreted as seeing and pay close attention to the symptoms that appear. Class observation is an observation technique carried out by supervisors on the ongoing learning process. In general, the aspects observed during the ongoing learning process are:

a. Teacher-student efforts and activities in the learning process.

b. How to use learning media.

c. Mental reactions of students in the teaching and learning process.

$\mathrm{d}$. The state of the learning media used in terms of the material.

3) Individual meeting

An individual meeting is a meeting, conversation, dialogue, and exchange of ideas between the coach or teacher, supervisor, teacher and teacher, regarding efforts to improve teacher professional abilities. In the case of this individual conversation, the supervisor must try to develop the positive aspects of the teacher, encourage the teacher to overcome his difficulties and provide direction, things that are still doubtful so that there is a conceptual agreement about the learning situation at hand.

4) Inter-Class visit Inter-class visits can also be classified as an individual supervision technique. Teachers are from one visit to another class in the school environment itself. With these inter-class visits, teachers will gain new experiences from their peers regarding the implementation of the classroom management learning process, and so on.

5) Assess Yourself

Self-assessment is an individual technique in educational supervision. Self-assessment is a teacher professional development technique. Self-assessment provides teachers with objective information about their role in the classroom and provides opportunities for teachers to learn the method of self-assessment which is not an easy task for teachers. To measure his teaching ability, in addition to assessing his students, also assessing himself.

\section{Group Supervision Techniques}

According to Gwynn, there are thirteen group supervision techniques, as follows:

1) Committees

2) Group work

3) Curriculum laboratory

4) Guided reading

5) Demonstration of learning

6) Excursions

7) Lecture/study

8) Panel discussion

9) Job library

10)Professional organization

11)Supervision bulletin

12) Teacher meeting

13)Group workshop or conference

Establishing appropriate academic supervision techniques is not easy. A school principal in addition to having to know the aspects or areas of skills to be fostered must also know the characteristics of each of the above techniques and the nature or personality of the teacher, so that the techniques used are truly by the teacher being fostered through academic supervision.

Based on the description above, the researcher made a hypothetical action, namely "There is an increase in the ability of teachers to prepare innovative lesson plans during the Covid-19 
Pandemic through the Academic supervision program at SMA Negeri 1 Puloampel in the 2020/2021 academic year".

\section{METHOD}

\section{Research Place}

The School Action Research was carried out in my school, namely SMAN 1 Puloampel, Serang Regency, Banten Province.

The selection of these schools aims to improve teacher competence in preparing innovative Learning Implementation Plans (RPP) during the Covid-19 Pandemic for the 2020/2021 Academic Year.

\section{Research time}

This School Action Research (PTS) is carried out in the odd semester and even semester of the 2020/2021 school year for approximately 6 months from October 2020 to March 2021.

\section{Research Implementation Schedule}

The schedule for conducting the research is as shown in the following table.

Table 1. The schedule for conducting the research

\begin{tabular}{lcccccc}
\hline \multirow{2}{*}{ Activity } & \multicolumn{5}{c}{ Month } \\
\cline { 2 - 7 } & Oct. '20 & Nov.'20 & Dec.'20 & Jan. '21 & Feb. '21 & Mar. '21 \\
\hline Making a Proposal & $\checkmark$ & $\checkmark$ & & & & \\
\hline Composing Instruments & & & $\checkmark$ & $\checkmark$ & & \\
\hline Data collection & & & & $\checkmark$ & \\
\hline Analyzing Data & & & & $\checkmark$ & $\checkmark$ \\
\hline $\begin{array}{l}\text { Compilation of PTS Laporan } \\
\text { Reports }\end{array}$ & & & & & $\checkmark$ \\
\hline PTS Report Presentation & & & & & $\checkmark$ \\
\hline
\end{tabular}

\section{Research Cycle}

School Action Research was carried out in two cycles to see the improvement of teacher competence in developing innovative Learning Implementation Plans (RPP).

\section{School Action Research Preparation}

Before the School Action Research (PTS) was carried out, various input instruments were made that were used to obtain data and information.

\section{Research Subject}

The subjects in this PTS are the Mathematics and Social Sciences subject teachers at SMAN 1 Puloampel, Serang Regency, Banten Province and based on the results of the investigation of the school led by the researcher.

\section{Data Source}

The source of data in this PTS is the Learning Implementation Plan that has been made by 8 teachers of SMAN 1 Puloampel, Serang Regency, Banten Province, consisting of 4 teachers who cover the MIPA (Mathematics and Natural Sciences) subject group and 4 teachers who cover the subjects IPS (Social Sciences).

\section{Data Collection Techniques and Tools}

1) Technique

Data collection techniques in this study were interviews, observation, and discussion.

2) Data Collection Tools

The data collection tools in this PTS are as follows:

a) The interview uses an interview guide to determine initial abilities teachers have about the 2013 Curriculum Learning Implementation Plan. 
b) Observation using the observation sheet to find out the components of the Curriculum RPP 2013 innovative ones that have been made and those that have not been made by the teacher.

c) The discussion was conducted to share opinions between researchers and teachers.

d) RPP Assessment Sheet

In this RPP assessment sheet, there are several criteria to assess whether the RPP is innovative. The criteria are as follows:

a) Formulating Indicators.

b) Formulating KBM Steps (Teaching and Learning Activities).

c) Allocate Time.

d) Determining Learning Resources.

e) Formulating Teaching Methods.

f) Formulating an Assessment.

Some of the criteria in the RPP assessment sheet above (Formulating Indicators, Formulating KBM Steps, Allocating Time, Determining Learning Resources, Formulating Teaching Methods and Formulating Assessments) will be assessed based on the theory of innovation in RPP preparation, namely whether they have Novelty, Integration, Added Value, Answering Problems and Produce.

\section{Supervision Models and Techniques}

The supervision model used is scientific supervision, namely capturing data or information and assessing teacher performance by distributing questionnaires. This supervision is scientific which has the following characteristics:

a) Implemented in a planned and sustainable manner.

b) Systematic and using certain procedures and techniques

c) Using data collection instruments.

d) Can collect objective data.

Meanwhile, the Supervision Technique used is individual in the form of class visits and virtual class observations due to the COVID-19 pandemic atmosphere and individual meetings.

\section{Research Procedure}

This research is in the form of School Action Research, which is a research that is a collaboration between researchers and teachers as well as supervisors, in improving the ability of teachers to become better at developing innovative Learning Implementation Plans.

The method used in this research is the descriptive method, using the percentage technique to see the increase that occurs from cycle to cycle. "Descriptive method can be defined as a problemsolving procedure that is investigated by describing/describing the state of the research subject/object (a person, institution, community, etc.) at present based on the facts that appear or as they are.

With this descriptive method, the researcher tries to explain the data that the researcher collects through direct communication or interviews, observations/observations, and discussions in the form of percentages or numbers.

This study aims to describe the difficulties experienced by teachers in preparing lesson plans. Furthermore, researchers provide alternatives or efforts to improve the ability of teachers in making lesson plans.The important things to consider in this School Action Research are:
a) Planning
b) Action
c) Observing
d) Reflection 
The PTS flow can be seen in the following figure:

\section{Figure 1. PTS steps}

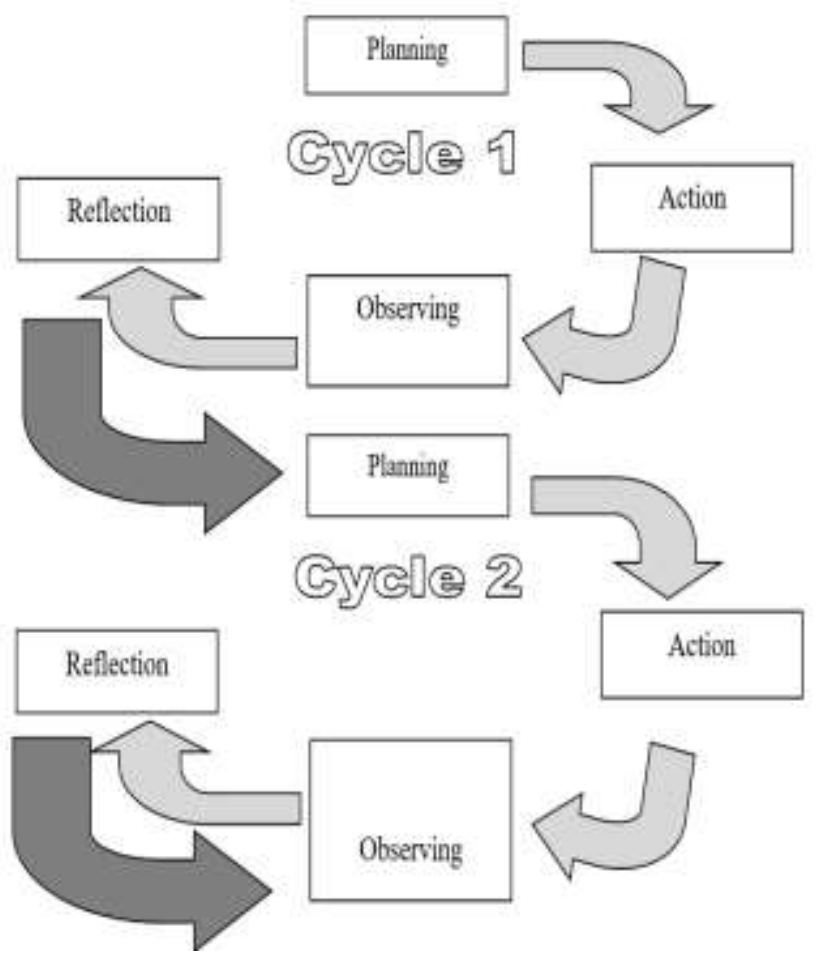

\section{Implementation Plan}

The implementation plan is carried out in two cycles, namely:

Cycle 1

a) Researchers plan actions in cycle 1 (making interview formats/instruments, assessment of the 2013 Curriculum RPP, recapitulation of the results of the 2013 Curriculum RPP preparation).

b) Researchers provide opportunities for teachers to express difficulties or obstacles in preparing the 2013 Curriculum Learning Implementation Plan.

c) The researcher explained to the teacher the importance of the innovative 2013 Curriculum RPP.

d) Researchers conduct academic supervision of individual scientific and technical supervision models in developing innovative 2013 Curriculum RPP.

e) Researchers made observations on the 2013 Curriculum RPP that the teacher had made.

f) Researchers revise or improve the preparation of innovative learning implementation plans.

g) Researchers and teachers do reflection.

Cycle 2

a) Researchers plan actions in cycle 2 based on revisions/improvements in cycle $I$, such as assigning teachers to prepare the second 2013 Curriculum RPP, collecting, and conducting academic supervision of individual scientific and technical supervision models in the form of mentoring in the preparation of innovative 2013 Curriculum RPP.

b) Researchers carry out actions according to the plan in cycle 2 .

c) Researchers made observations on the 2013 Curriculum RPP that the teacher had made.

d) Researchers make improvements or revisions to the preparation of the 2013 Curriculum RPP which innovative.

e) Researchers and teachers do reflection. 


\section{Indicators of Achievement Results}

Researchers expect at least $60 \%$ of teachers to make 6 (six) innovative Learning Implementation Plan (RPP) assessment components, namely Component Formulating Indicators, Formulating KBM Steps, Allocating Time, Determining Learning Resources, Formulating Teaching Methods and Formulating Assessment Components.

\section{RESULT AND DISCUSSION}

From the results of interviews and recordings of 8 (eight) teachers (four MIPA teachers and four social studies teachers), researchers obtained information that many teachers did not fully understand the framework for preparing innovative 2013 Curriculum RPP and the steps of Covid19 pandemic learning. Only two teachers have participated in the 2013 Curriculum RPP development training. Most teachers adopt and adapt the 2013 Curriculum RPP, also teachers do not know and do not fully understand the preparation of the 2013 Curriculum RPP which is innovative and by learning during the Covid-19 pandemic. They agree that teachers should use the innovative 2013 Curriculum RPP in implementing the learning process which can be used as a reference/guideline in the current distance learning process.

The components of the 2013 Curriculum RPP are so many that it becomes confusing for teachers to compile them, added with the latest RPP ( 1 sheet RPP) as well as innovative steps during the Covid-19 pandemic learning period. The latest circular from the Minister of Education and Culture number 14 of 2019 is one of the 4 Free Learning Concepts, namely the RPP (Learning Implementation Plan). This RPP is in the form of a Simplification of RPP, which makes it easier for teachers to make it. This RPP is enough to make only one page and can be added with other RPP components. Through administrative simplification, it is hoped that teacher time in administration can be diverted for learning activities and competency improvement.

Based on the results of researchers' observations of 8 (eight) innovative RPP 2013 Curriculum that have been made by teachers (especially in cycle 1), information/data is obtained, including in the Indicator Formulation component there are still teachers who do not complete their RPP with certain RPP components and sub-components, for example, in the Learning Objectives, the formulation of indicators using Operational Verbs (KKO) is not yet appropriate. The formulation of student activities on the components of the steps of learning activities is still not sharp, interactive, inspiring, challenging, systematic and innovative and there are still those who have not adjusted their learning steps to the Covid-19 Pandemic situation or adapted to Distance Learning (PBJJ).

In terms of teacher competence, there was an increase in preparing the Learning Implementation Plan from cycle to cycle. This can be seen in the attachment of the Recapitulation of the Results of the Innovative 2013 Curriculum RPP from Cycle to Cycle.

\section{Cycle 1}

The first cycle consists of four stages, namely: (1) planning, (2) action, (3) observation, and (4) reflection as follows:

1) Planning

a) Making interview sheets

b) Creating an innovative 2013 Curriculum RPP assessment format/instrument.

c) Make a recapitulation format of the results of the preparation of the 2013 Curriculum RPP from the third cycle.

2) Action

At the beginning of the first cycle in the Components of Formulating Indicators in the Learning Objectives, many did not match the plans/wants of the researcher. This is evidenced by the existence of overlapping Operational Verbs (KKO), not sorted from easy to difficult. There has 
not been an innovation in making lesson plans that can challenge students to learn more actively.

In the core activity, there are still some teachers whose learning activities do not reflect 21stcentury skills such as the integration of PPK (Strengthening Character Education), Literacy, HOTS (High Order Thinking Skills) and 4C (Creative, Critical thinking, Communicative, and Collaborative).

In the assessment of innovative RPP (Formulating Indicators, Formulating KBM Steps, Allocating Time, Determining Learning Resources, Formulating Teaching Methods and Formulating Assessments), there are still many teachers who have not adjusted it.

3) Observing

The results of observations in the first cycle can be described as follows:

Observations were carried out on Wednesday 10 February 2021 for eight teachers. All of them prepare innovative RPP 2013 Curriculum but there are still teachers who have not completed their RPP either with components or sub-components of certain innovative RPP. For the components of the innovative RPP assessment, it can be stated as follows:

a) Four people have not used the right indicator formula.

b) Two people have not used the KBM step formula that is integrated with 21st-century prowess skills.

c) One person did not complete the correct time allocation.

d) Two people have not used learning resources properly.

e) Two people have not formulated a teaching method that is by Basic Competence (KD).

f) Four people have not formulated the assessment properly.

4) Reflecting

The results of cycle 1 above were then discussed with the observer (Supervisor) and produced several notes, including the following:

a) The process of developing an innovative RPP carried out by 8 teachers at SMAN 1 Puloampel, Serang Regency, Banten Province, consisted of 4 teachers who taught the MIPA (Mathematics and Natural Sciences) subject group and 4 teachers who taught IPS (Social Sciences) subjects, is good enough, but must still pay attention to teachers who still do not meet the elements of making innovative lesson plans, especially in terms of using the formulation of indicators and formulation of assessments.

b) Researchers through academic supervision of scientific supervision models and individual techniques guide teachers who have difficulty in making innovative lesson plans to complete their lesson plans again in the next meeting (next cycle), especially in terms of using indicator formulations and formulation of assessments and other aspects while still using the same basic competence (KD) of each subject they teach.

\section{Cycle 2}

The second cycle also consists of four stages, namely: (1) planning, (2) action, (3) observing, and (4) reflection. The results of observations in the second cycle can be described as follows:

Observations were carried out on Tuesday, March 9, 2021, on eight teachers. All of them developed an innovative 2013 Curriculum RPP.

The results of observations in the second cycle can be described as follows:

Observations were carried out on Wednesday 10 February 2021 for eight teachers. All of them developed an innovative 2013 Curriculum RPP. The components of the innovative RPP assessment in the second cycle can be stated as follows:

a) Two people have not used the right indicator formula.

b) One person has not used the KBM step formula that is integrated with $21^{\text {st-century }}$ prowess skills. 
c) All teachers complete the time allocation correctly.

d) One person has not used learning resources properly.

e) One person has not formulated a teaching method that is by Basic Competence (KD).

f) One person has not formulated the assessment properly.

There was a significant increase compared to the first cycle stage. Furthermore, these teachers $(8$ teachers) consisting of 4 Mathematics and Natural Sciences teachers and 4 Social Science subject teachers were still guided by the researchers through academic supervision of scientific supervision models and individual techniques to further refine their innovative lesson plans.

The School Action Research was conducted at SMAN 1 Puloampel, Serang Regency, which is the research school with the status of a State, consisting of eight teachers studied (4 Mathematics and Natural Sciences teachers and 4 Social Studies teachers), and was carried out in two cycles. The eight teachers showed a good attitude and were motivated in preparing the innovative 2013 Curriculum RPP. This the researcher knows from the observations at the time of conducting interviews and assisting in the preparation of the RPP.

Furthermore, judging from the competence of teachers in preparing innovative 2013 Curriculum RPP, there was an increase from cycle to cycle.

1) Components of Formulating Indicators

In the first cycle all the teachers studied, namely 8 teachers (4 MIPA subject teachers and 4 social studies teachers) included the formulation of indicators and if it was a percentage, it was $53.2 \%$. Four teachers have not formulated indicators well and got an average score of 5.6 and four more teachers have formulated indicators well and got an average score of 7.7. In the second cycle, the six teachers included the formulation of indicators in their lesson plans well, with an average score of 7.9. Meanwhile, two other teachers whose indicator formulations get an average score of 6.4 and if it is a percentage of $60.02 \%$, there is an increase of $7 \%$ from cycle I.

2) Components of Formulating KBM Steps

In the first cycle, all the teachers studied, namely 8 teachers (4 MIPA subject teachers and 4 social studies teachers) included the formulation of the KBM steps and if they were presented as a percentage, it was 59\%. Two teachers have not formulated the KBM steps well and got an average score of 6 and another six teachers have formulated the KBM steps well and got an average score of 7.83. In the second cycle the seven teachers included the formulation of the KBM steps in The RPP is good, with an average score of 8.25. Meanwhile, one more teacher formulating the KBM steps gets a score of 6.2 and if it is presented as a percentage of $64 \%$, there is an increase of $5 \%$ from cycle I.

3) Component Allocating Time

In the first cycle, all the teachers studied, namely 8 teachers (4 MIPA subject teachers and 4 social studies teachers) included the Time Allocation and if it was a percentage it was $52.7 \%$. One teacher has not allocated time well and got a score of 5.8 and seven other teachers have allocated time well and got an average score of 6.7. In the second cycle, all the teachers studied ( 8 teachers, 4 MIPA subject teachers and 4 social studies teachers) allocated time in their lesson plans well, with an average score of 9.2. If the percentage is $73.6 \%$, there is an increase of $20.9 \%$ from the first cycle.

4) Components of Determining Learning Resources

In the first cycle all the teachers studied, namely 8 teachers (4 MIPA subject teachers and 4 social studies teachers) included the components of learning resources and if they were presented as a percentage, it was $53.76 \%$. Two teachers have not determined learning resources well and got an average score of 5.7 and six other teachers have determined learning resources well and got an average score of 7.06. In the second cycle of all the teachers studied ( 8 teachers, 4 MIPA subject teachers and 4 social studies teachers), one person has not determined the 
learning resources in their lesson plans well, with a score of 6.0. While the other seven teachers have determined learning resources well with an average score of 7.8. If the percentage is $60.6 \%$, there is an increase of $6.84 \%$ from the first cycle.

5) Components of Formulating Teaching Method

In the first cycle, all the teachers studied, namely 8 teachers (4 MIPA subject teachers and 4 social studies teachers) included the formulation of teaching methods and if it was a percentage, it was $58.6 \%$. Two teachers have not determined the formulation of teaching methods well and got an average score of 5.9 and six other teachers have determined the formulation of teaching methods well and got an average score of 7.8. In the second cycle, all the teachers studied (8 teachers, 4 MIPA subject teachers and 4 social studies teachers), one person has not determined the formulation of the teaching method in his RPP properly, with a score of 6 . While the other seven teachers have determined the formulation of teaching methods well with an average score of 8.02 and if it is presented as a percentage of $62.14 \%$, there is an increase of $3.54 \%$ from cycle 1 .

6) Components of Formulating Assessment

In the first cycle all the teachers studied, namely 8 teachers (4 MIPA subject teachers and 4 social studies teachers) included the assessment formula and if it was a percentage, it was $51.4 \%$. Four teachers have not determined the formulation of the assessment well and got an average score of 5.65 and four more teachers have determined the formulation of the assessment well and got an average score of 7.2. In the second cycle, all the teachers studied (8 teachers, 4 MIPA subject teachers and 4 social studies teachers), one person had not yet determined the formulation of the assessment in his RPP properly, with a score of 5.8. While the other seven teachers have determined the formulation of the assessment well with an average score of 7.8 and if the percentage is $60.4 \%$, there is an increase of $9 \%$ from cycle 1 .

Based on the discussion above, there is an increase in teacher competence in preparing innovative RPP. In the first cycle, the average value of the 2013 curriculum RPP component is $68.4 \%$, in the second cycle, the 2013 curriculum RPP component average value is $77.6 \%$, an increase of $9.2 \%$.

To find out more clearly the improvement of each component of the innovative 2013 Curriculum RPP, it can be seen in the appendix of the Recapitulation of the 2013 Curriculum RPP Preparation from Cycle to Cycle at SMAN 1 Puloampel, Serang Regency, Banten Province.

\section{CONCLUSIONS}

Based on the results of School Action Research (PTS), it can be concluded as follows:

1) Academic Supervision can improve the ability of teachers in preparing innovative 2013 Curriculum RPP. The teacher shows seriousness in understanding and compiling the innovative 2013 Curriculum RPP after receiving guidance on developing/compiling the RPP from the researcher.

2) Through the academic supervision program during the COVID-19 pandemic for the 2020/2021 school year, it can improve teacher competence in preparing innovative 2013 Curriculum RPP. This can be proven from the results of observations which show that there is an increase in teacher competence in preparing innovative 2013 Curriculum RPP from cycle to cycle.

From the results of this study, it is recommended:

1) This research can get special attention from school principals as well as supervisors and educators in general.

2) Academic supervision must be carried out by school principals to get better learning quality, especially in implementing the 2013 Curriculum, one of which is making good and innovative RPP because it is a reference/guideline in implementing the learning.

3) Hopefully this research can become a knowledge sharing with colleagues, especially in the educational unit environment. 


\section{REFERENCES}

Ali, Imron, 2009. Penelitian Tindakan Sekolah Untuk Kepala Sekolah Dalam Rangka peningkatan Kinerja Pembelajaran, Dirjen PMPTK, Depdiknas.

Arikunto,S., 2012. Penelitian Tindakan Kelas. Bumi Aksara, BPG Semarang

Gorski, P.C., 2015. Teacher Action Research. Critical Multicultural Pavilion, an edChange Project. George Masion University. Teaching and Teacher Education 309-318.

Kemendiknas. 2015. Penelitian Tindakan Sekolah. Jakarta.

Mulyasa, E., 2011. Praktik Penelitian Tindakan Kelas. PT Remaja Rosdakarya, Bandung

Rubiyanto, Rubino. 2009. Metode Penelitian Pendidikan. Surakarta: UMS

Sanjaya, Wina. 2008. Strategi Pembelajaran. Jakarta: Prenata Media

Sudjana, Nana. 2009. Standar Kompetensi Pengawas Dimensi dan Indikator. Jakarta: Binamitra Publishing. 